\title{
Simulations of the Light Scattering Properties of Metal/Oxide Core/Shell Nanospheres
}

\author{
F. Ruffino, ${ }^{1,2}$ G. Piccitto, ${ }^{1}$ and M. G. Grimaldi ${ }^{1,2}$ \\ ${ }^{1}$ Dipartimento di Fisica ed Astronomia, Università di Catania, Via S. Sofia 64, 95123 Catania, Italy \\ ${ }^{2}$ MATIS IMM-CNR, Via S. Sofia 64, 95123 Catania, Italy \\ Correspondence should be addressed to F. Ruffino; francesco.ruffino@ct.infn.it \\ Received 3 December 2013; Revised 3 March 2014; Accepted 6 March 2014; Published 6 April 2014 \\ Academic Editor: Oleg I. Lupan
}

Copyright (C) 2014 F. Ruffino et al. This is an open access article distributed under the Creative Commons Attribution License, which permits unrestricted use, distribution, and reproduction in any medium, provided the original work is properly cited.

\begin{abstract}
Given the importance of the optical properties of metal/dielectric core/shell nanoparticles, in this work we focus our attention on the light scattering properties, within the Mie framework, of some specific categories of these noteworthy nanostructures. In particular, we report theoretical results of angle-dependent light scattering intensity and scattering efficiency for $\mathrm{Ag} / \mathrm{Ag} 2 \mathrm{O}$, $\mathrm{Al} / \mathrm{Al}_{2} \mathrm{O}_{2}, \mathrm{Cu} / \mathrm{Cu}_{2} \mathrm{O}, \mathrm{Pd} / \mathrm{PdO}$, and $\mathrm{Ti} / \mathrm{TiO}_{2}$ core/shell nanoparticles as a function of the core radius/shell thickness ratio and on a relative comparison. The results highlight the light scattering characteristics of these systems as a function of the radius/shell thickness ratio, helping in the choice of the more suitable materials and sizes for specific applications (i.e., dynamic light scattering for biological and molecular recognition, increasing light trapping in thin-film silicon, organic solar cells for achieving a higher photocurrent).
\end{abstract}

\section{Introduction}

Metal nanoparticles (NPs) have been extensively studied in recent years due to their wide range of potential applications [1-11]. In particular, the increase in the local electric field produced by the localized surface plasmon resonance (LSPR) [1-4] is useful for several linear [12] and nonlinear $[13,14]$ optical processes. In fact, metal NPs can exhibit extraordinary optical resonances: when excited by electromagnetic radiation they can exhibit LSPR due to the collective oscillations of their conduction electrons [1-4]. The resonant excitation of LSPR leads to selective photon absorption and enhancement of local electromagnetic fields near the NPs by orders of magnitude. The possibility of controllably tuning the LSPR wavelength through the visible to near infrared region makes metal NPs very important and promising for the technological applications. In addition to their LSPR absorption, light scattering is another optical property of metal NPs that is of great interest $[1-4,15-18]$. When NPs are illuminated with a beam of light at a wavelength $\left(\lambda_{0}\right)$ that matches the plasmon absorption maxima $\left(\lambda_{p}\right)$, the NPs can both absorb and scatter light outside of their physical cross-sections. So, also, dynamic light scattering by metal NPs is, today, widely used as a powerful tool in biological and molecular recognition $[6,7]$ and to increase the light trapping in thin-film silicon and organic solar cells for achieving a higher photocurrent [8-14] (Mie scattering [15-18] plays an essential role in increasing the optical path length). Scattering and plasmon optical properties, such as peak wavelength, full width at half maximum, and contrast, strongly depend on the material, size, shape, and structure of the NPs, as well as on the surrounding media. As a consequence, in addition to pure metal NPs, recently, also metal/dielectric core/shell NPs are widely studied for the improvement and manipulation of the scattering and plasmon resonances properties. For coated (core-shell) NPs, these characteristics are strongly influenced by the presence of the shell: the position of the LSPR and the angular-dependent scattered light intensity can be tuned by varying the ratio between the core radius and the thickness of the oxide layer making these nanostructures technologically versatile [19-39]. Some works deal with the fabrication, by both physical and chemical methodologies, and study core/shell NPs formed by a metal core and its own oxide as a shell: $\mathrm{Ag} / \mathrm{Ag}_{2} \mathrm{O}$ [23-27], $\mathrm{Al} / \mathrm{Al}_{2} \mathrm{O}_{3}$ [28-31], $\mathrm{Cu} / \mathrm{Cu}_{2} \mathrm{O}$ [32-36], $\mathrm{Pd} / \mathrm{PdO}[37,38]$, and $\mathrm{Ti} / \mathrm{TiO}_{2}$ [39]. These 


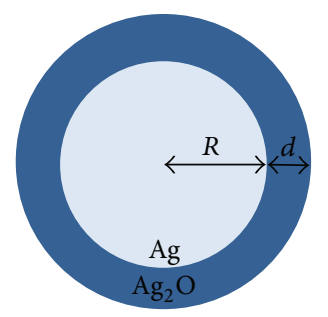

(a)

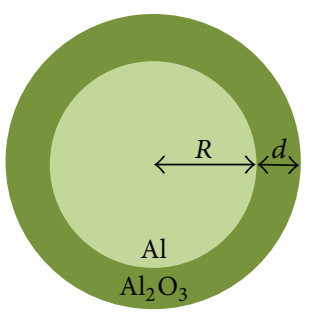

(b)

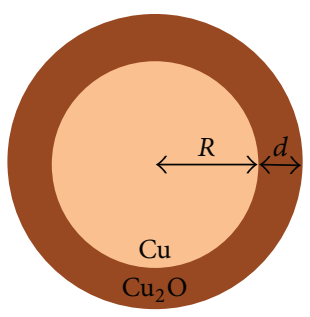

(c)

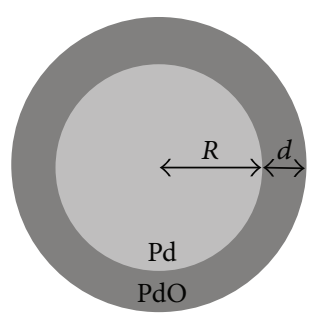

(d)

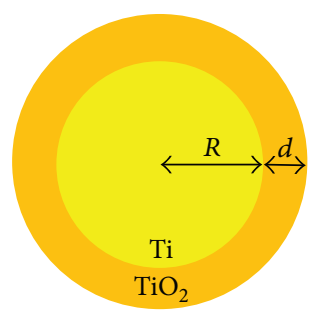

(e)

FIGURE 1: Scheme of the metal/dielectric core/shell nanospheres analyzed. $R$ is the metal core radius and $d$ is the dielectric shell thickness.

works triggered an increasing need for the study of the optical response of such nanostructures as a function of size of the core and of the shell [25-27, 30, 34, 35, 37]. For example, Santillán et al. [26] reported data on the optical extinction of $\mathrm{Ag} / \mathrm{Ag}_{2} \mathrm{O}$ core/shell NPs, Kuzma et al. [27] reported data about the influence of the surface oxidation on plasmon resonance in monolayer of Ag NPs, Peng et al. [30] reported data about the absorption spectra of $\mathrm{Al} / \mathrm{Al}_{2} \mathrm{O}_{3}$ core/shell NPs, Ghodselahi et al. [34] reported data about surface plasmon resonance of $\mathrm{Cu} / \mathrm{Cu}_{2} \mathrm{O}$ core/shell NPs, Peña-Rodríguez and Umapada [35] reported data on the effects of surface oxidation on the linear optical properties of $\mathrm{Cu}$ NP, Xiong et al. [37] reported data on the size dependence surface plasmon resonance in oxidated Pd nanostructures. On the basis of the interest in the optical response of the core shell NPs, in this work we focus our attention, in particular, on the light scattering properties of $\mathrm{Ag} / \mathrm{Ag} 2 \mathrm{O}, \mathrm{Al} / \mathrm{Al}_{2} \mathrm{O}_{3}$, $\mathrm{Cu} / \mathrm{Cu}_{2} \mathrm{O}, \mathrm{Pd} / \mathrm{PdO}$, and $\mathrm{Ti} / \mathrm{TiO}_{2}$ core/shell NPs as a function of the core radius/shell thickness ratio and on a relative comparison (Figure 1). In particular, we report theoretical results about the angle-dependent light scattering properties of spherical NPs (nanospheres, NSPs) on the basis of a generalized Mie approach. So, after a short recall, in Section 2, of the theoretical basic concepts to treat the light scattering phenomena from small homogeneous and layered spherical particles as known in the literature on the basis of the Mie approach [17, 18, 40-42], in Section 3 we will report the results for the simulation of the light scattering intensity, using the SCATLAB simulation software [43], for $\mathrm{Ag} / \mathrm{Ag}_{2} \mathrm{O}, \mathrm{Al} / \mathrm{Al}_{2} \mathrm{O}_{3}$, $\mathrm{Cu} / \mathrm{Cu}_{2} \mathrm{O}, \mathrm{Pd} / \mathrm{PdO}$, and $\mathrm{Ti} / \mathrm{TiO}_{2}$ core/shell NSPs increasing the particle radius $R$ from 30 to $110 \mathrm{~nm}$ and the shell thickness $d$ from 0 to $80 \mathrm{~nm}$ (Figure 1). Finally, a comparison between the scattering efficiency of these core/shell NSPs will be drawn.

The results exposed in this work can be of help in the design of tunable efficiency light scattering devices (biological and molecular sensors, solar cells).

\section{Theory Concepts}

Interaction of electromagnetic radiation with particles is well studied [15-18, 40-42]. The classical theory by Mie [40] gives an analytical solution for scattering from homogenous particles. Theoretical studies on the optical properties of multilayer spherical [42] and planar [41] particles are reported in the literature. In particular, for our general discussion, in this section we expose the basic concepts of the theory for scattering of electromagnetic waves by core-shell materials following the considerations of Small et al. [42]. The solution under appropriate conditions gives the same expression as Mie theory for single sphere.

The important parameter to treat the scattering process of electromagnetic radiation from a particle (i.e., a welldefined aggregate of many atoms or molecules) embedded in an otherwise homogeneous medium (in the sense that the atomic or molecular heterogeneity is small compared with the wavelength of the incident light) is the scattering cross-section $\sigma$. It is the ratio of the total scattered power to the radiation intensity. The cross section $\sigma$ (units of area) is proportional to the total amount of light scattered by a particle when illuminated by a plane wave. Supposing to illuminate a particle with a plane wave of intensity $I_{0}$ (energy/area/time), and by detectors to measure the power scattered in each direction, by integrating the measured over all directions, we obtain the total scattered power $W$ (energy/time). The scattering cross section (i.e., the ratio of the total radiant power scattered by a particle in all directions to the radiant power incident on the particle, or, also, the number of photons scattered by particle through any scattering angle) is

$$
\sigma=\frac{W}{I_{0}} .
$$

The scattering cross section is converted to scattering efficiency $\left(Q_{\text {scatt }}\right)$ which is the normalized scattering cross section to the geometrical cross section:

$$
Q_{\text {scatt }}=\frac{\sigma}{\pi R^{2}},
$$

being $R$ the radius of the particle. $Q_{\text {scatt }}$ has the advantage of being a dimensionless number so that it can be used to compare particles of different sizes. $Q_{\text {scatt }}$ can exceed 1 since in addition to scattering light incident on their geometrical cross section, particles also diffract light at their edges, so a particle can behave larger than its geometrical cross section. By solving Maxwell's equations for a plane wave incident on a layered spherical particle $\sigma$ can be calculated (for a homogeneous particle the first exact analytical solution was given by Mie [40]). To a qualitatively understanding 


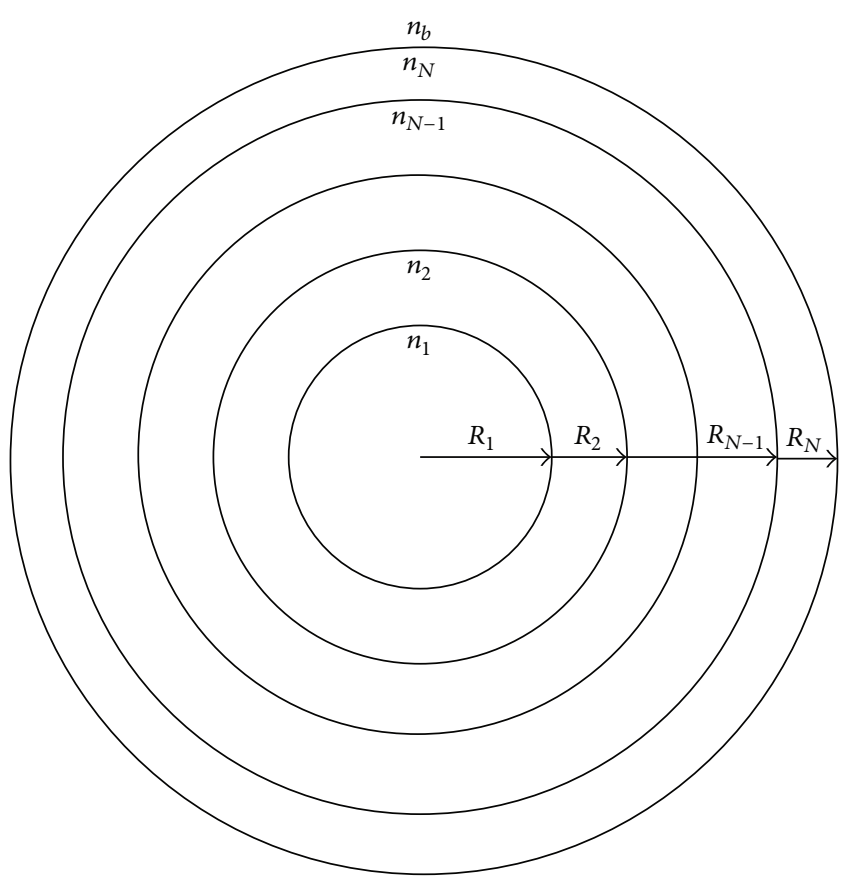

FIGURE 2: Scheme of layered particle with variables $R_{j}, n_{j}$, and $n_{b}$ illustrated.

of the physics of scattering by a single particle, we can consider an arbitrary particle, as conceptually subdividing into small regions. An applied oscillating field (e.g., an incident electromagnetic wave) induces a dipole moment in each region. These dipoles oscillate at the frequency of the applied field and therefore scatter secondary radiation in all directions. In a particular direction, the total scattered field is obtained by superposing the scattered wavelets, where due account is taken of their phase differences: scattering by the dipoles is coherent. In general, these phase relations change for a different scattering direction; we therefore expect the scattered field to vary with scattering direction. If the particle is small compared with the wavelength, all the secondary waves are approximately in phase; for such a particle we do not expect much variation of scattering with direction. As the particle size is increased, however, the number of possibilities for mutual enhancement and cancellation of the scattered wavelets increases. Thus, the larger the particle, the more peaks and valleys in the scattering pattern [17]. For a layered particle it is possible to use the Mie theory in a form that will be useful for making analogies with waves in planar dielectric coatings [42]. We consider a spherical particle with $N$ layers, with layer 1 being the core and layer $N$ the outermost shell (Figure 2). Each layer has radius $R_{j}$ and refractive index $n_{j}$ (with the parameter being the manifestation of scattering by the many molecules that compose the medium). The particle is embedded in a background matrix of refractive index $n_{b}$. Because of spherical symmetry, the incident, scattered, and internal fields can be expanded as a superposition of vector spherical harmonics. So we can solve the boundary value problem to determine the expansion coefficients of the vector spherical harmonics. At each boundary between two distinct media, the electromagnetic fields have to satisfy Maxwell's boundary conditions. For a multilayered sphere, in principle, there are three different boundaries to take into in account: (i) the boundary between the core and the innermost shell, (ii) the boundary between two shells, and (iii) the boundary between the particle and the embedding medium. For the latter, they connect the electromagnetic fields of the incident wave and the scattered wave with the wave in the outermost shell. For the quantitative analyses, we call $\mathbf{N}_{m p}\left(k_{0} n r, \theta, \phi\right)$ the function describing the waves radiating outwards from the origin and $\mathbf{N}_{m p}^{*}\left(k_{0} n r, \theta, \phi\right)$ for waves converging inward toward the origin. The superscript * denotes complex conjugation, $k_{0}=2 \pi / c$ ( $c$ the light velocity in vacuum), $n$ is the refractive index of the medium that the wave is traveling in, and $r, \theta$, and $\Phi$ are the usual spherical coordinates. $p$ refers to the polarization of the wave and is 1 for transverse magnetic waves and 2 for transverse electric waves. The subscript $m$ refers to the order of the Hankel function of the first kind governing the radial dependence of the vector spherical harmonic [42]. At large distances from the origin the Hankel functions are proportional to $\left[\exp \left( \pm i k_{0} n r\right)\right] / k_{0} n r$, where the sign of the exponent depends on whether the wave radiates outward from the origin $(+)$ or converges inward toward the origin $(-)$. When the thickness of a layer is much smaller than the distance $r$ from the origin we can approximate the radial dependence of the field in that layer with a sinusoidal function. The plane wave incident on the particle can be written as [42]

$$
\mathbf{E}_{\mathrm{inc}}=\frac{1}{2} \sum_{p=1}^{2} \sum_{m=1}^{\infty} q_{m p}\left[\mathbf{N}_{m p}\left(k_{0} n_{b} r, \theta, \phi\right)+\mathbf{N}_{m p}^{*}\left(k_{0} n_{b} r, \theta, \phi\right)\right],
$$

where $q_{m p}=-\left[i^{n+p}(2 n+1) / n(n+1)\right]$. The scattered field can be written as [42]

$$
\mathbf{E}_{\text {scatt }}=\sum_{p=1}^{2} \sum_{m=1}^{\infty} q_{m p} a_{m p} \mathbf{N}_{m p}\left(k_{0} n_{b} r, \theta, \phi\right),
$$

where $a_{m p}$ is proportional to a scattering amplitude. The coefficients $\left\{a_{m p}\right\}$ completely determine the scattered field. So, their calculation is the main aim in studying electromagnetic scattering by a particle. Once the scattered field is known, $\sigma$ can be calculated. The field in the $j$ th layer of the particle can be written in the following form:

$$
\begin{aligned}
\mathbf{E}_{\mathrm{int}}^{j}=\sum_{p=1}^{2} \sum_{m=1}^{\infty} q_{m p}[ & u_{m p}^{j} \mathbf{N}_{m p}\left(k_{0} n_{j} r, \theta, \phi\right) \\
& \left.+v_{m p}^{j} \mathbf{N}_{m p}^{*}\left(k_{0} n_{j} r, \theta, \phi\right)\right], \quad 2 \leq j \leq N,
\end{aligned}
$$

$\mathbf{E}_{\mathrm{int}}^{1}=\sum_{p=1}^{2} \sum_{m=1}^{\infty} q_{m p}\left[u_{m p}^{1} \mathbf{N}_{m p}\left(k_{0} n_{1} r, \theta, \phi\right)+\mathbf{N}_{m p}^{*}\left(k_{0} n_{1} r, \theta, \phi\right)\right]$, 
TABLE 1: Values of the real part of the particle metal core refractive index, of the imaginary part of the particle metal core refractive index, of the real part of the particle dielectric coat refractive index, and of the imaginary part of the particle dielectric coat refractive index, for wavelength $\lambda_{0}=550 \mathrm{~nm}$, used in the simulations [44-46].

\begin{tabular}{ccccccccccc}
\hline & $\mathrm{Ag}$ & $\mathrm{Al}$ & $\mathrm{Cu}$ & $\mathrm{Pd}$ & $\mathrm{Ti}$ & $\mathrm{Ag}_{2} \mathrm{O}$ & $\mathrm{Al}_{2} \mathrm{O}_{3}$ & $\mathrm{Cu}_{2} \mathrm{O}$ & $\mathrm{PdO}$ & $\mathrm{TiO}_{2}$ \\
\hline$n$ & 0.125 & 1.015 & 0.944 & 1.641 & 1.885 & 2.400 & 1.663 & 3.099 & 2.800 & 2.648 \\
$k$ & 3.339 & 6.627 & 2.595 & 3.848 & 2.609 & 0 & 0 & 0 & 0 & 0 \\
\hline
\end{tabular}
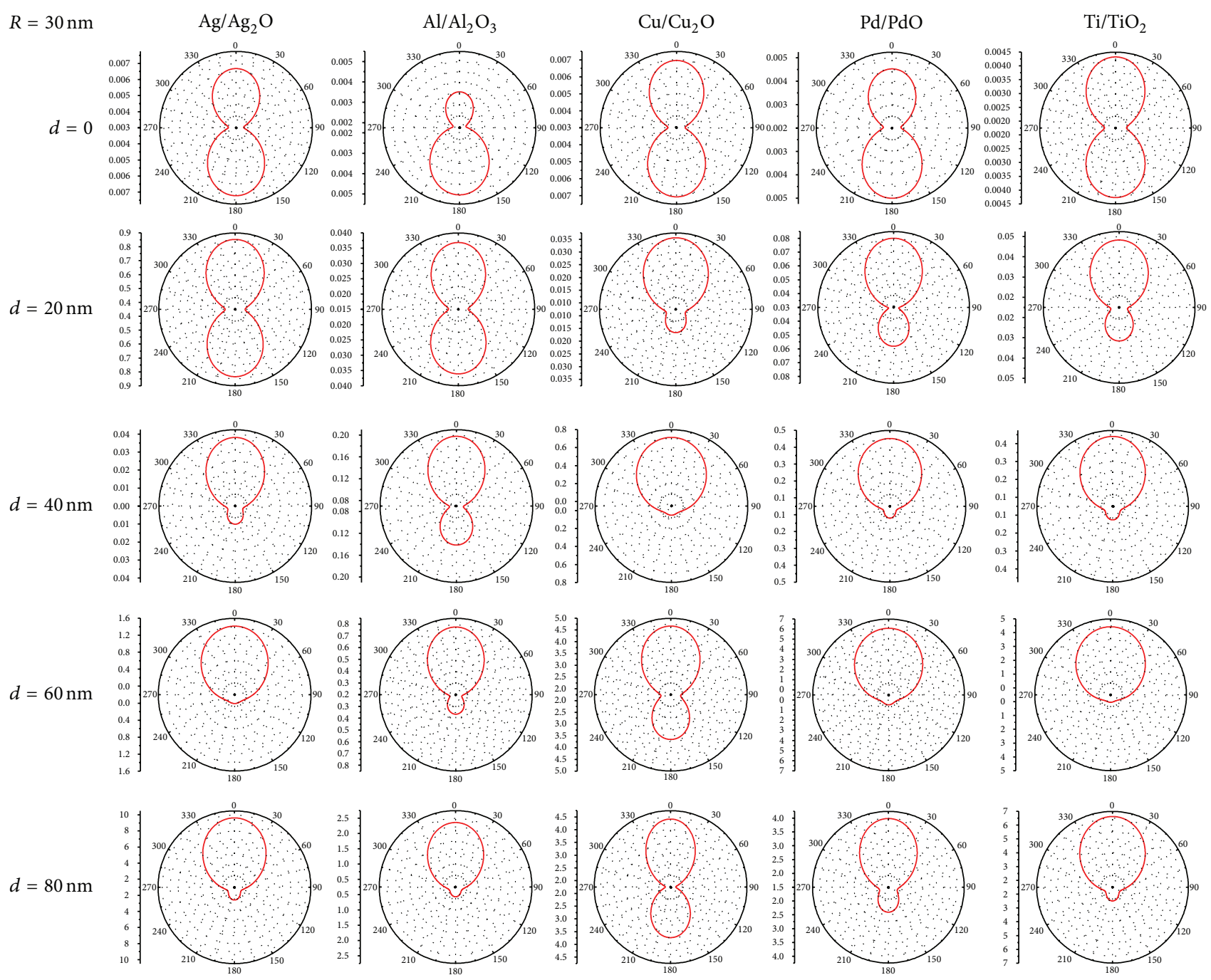

FIGURE 3: Calculated $I(\theta)$ polar diagrams for $\mathrm{Ag} / \mathrm{Ag}_{2} \mathrm{O}, \mathrm{Al} / \mathrm{Al}_{2} \mathrm{O}_{3}, \mathrm{Cu} / \mathrm{Cu}_{2} \mathrm{O}, \mathrm{Pd} / \mathrm{PdO}$, and $\mathrm{Ti} / \mathrm{TiO}_{2}$ core/shell spherical NPs with metal core radius $R=30 \mathrm{~nm}$ and dielectric shell thickness $d$ increasing from 0 to $80 \mathrm{~nm}$.

where $u_{m p}^{j}$ and $v_{m p}^{j}(j)$ are coefficients of the outgoing and incoming fields. In (6) the first boundary condition is imposed: at the core of the particle $u_{m p}^{1}=v_{m p}^{j}$. An incoming spherical wave front that converges toward the center of the particle will, upon reaching the center, diverge outward, and so the amplitudes of the incoming and outgoing fields must be equal at the center of the particle. The other boundary conditions are that the transverse components of the electric and magnetic fields are continuous across the boundary between layers $j$ and $j+1(1<j<N-1)$ and between layer $N$ and the surrounding matrix (note that the magnetic field $\mathbf{H}$ can be easily calculated from the Faraday equation once that $\mathrm{E}$ is known). These conditions yield a set of $2 \mathrm{~N}$ equations that we can solve to obtain the set of coefficients $\left\{a_{m p}\right\}$, which can then be used to obtain $\sigma$ for a given particle morphology.

This general methodology proposed by Small et al. [42] is very efficient in treating the light scattering problems from homogeneous and layered particles. It is in general very long and laborious but excellent algorithms and software 
are available to perform these calculations. In this paper, we used ScatLab 1.2 [43] for theoretical calculations. In this computer code the scattering cross sections $\left(Q_{\text {scatt }}\right)$ and angle-dependent intensities $(I(\theta))$ can be calculated for homogeneous and core-shell geometries.

\section{Calculations and Discussion}

ScatLab is a software developed by Bazhan to perform electromagnetic scattering simulations mainly based on classical Mie theory solution [43]. We used it to calculate the scattering properties of $\mathrm{Ag}, \mathrm{Al}, \mathrm{Cu}, \mathrm{Pd}$, and $\mathrm{Ti}$ spherical NPs of radius $R$ between 30 and $110 \mathrm{~nm}$, and of $\mathrm{Ag} / \mathrm{Ag}_{2} \mathrm{O}, \mathrm{Al} / \mathrm{Al}_{2} \mathrm{O}_{3}$, $\mathrm{Cu} / \mathrm{Cu}_{2} \mathrm{O}, \mathrm{Pd} / \mathrm{PdO}$, and $\mathrm{Ti} / \mathrm{TiO}_{2}$ core/shell spherical NPs with radius $R$ of the metal core varying between 30 and $90 \mathrm{~nm}$ and thickness $d$ of the dielectric shell between 20 and $80 \mathrm{~nm}$. The reported calculations are performed fixing, for example, a wavelength of $\lambda_{0}=550 \mathrm{~nm}$ of the incident radiation (the center of the visible spectrum). The input parameters in each simulation are the core radius $R$, the shell thickness $d$, the real part of the environment (air) refractive index $\left(n_{a}\right)$, the imaginary part of the environment (air) refractive index $\left(k_{a}\right)$, the real part of the particle metal core refractive index $\left(n_{m}\right)$, the imaginary part of the particle metal core refractive index $\left(k_{m}\right)$, the real part of the particle dielectric coat refractive index $\left(n_{d}\right)$, and the imaginary part of the particle dielectric coat refractive index $\left(k_{d}\right)$. For the chosen wavelength we use the values of $n_{a}=1, k_{a}=0$, and for $n_{m}, k_{m}, n_{d}, k_{d}$ the values are reported in Table 1 and extracted from [4446]. As output parameters we report the scattered intensity $I$ (arbitrary units) as a function of the scattering angle $\theta$ (degrees) in $I(\theta)$ polar diagrams and the scattering efficiency $Q_{\text {scatt }}$. In the polar diagrams, the wave impacts from $180^{\circ}$. Note, obviously, that we are always in a condition $R+d \ll \lambda_{0}$.

In Figure 3 we report the calculated $I(\theta)$ polar diagrams for $\mathrm{Ag} / \mathrm{Ag}_{2} \mathrm{O}, \mathrm{Al} / \mathrm{Al}_{2} \mathrm{O}_{3}, \mathrm{Cu} / \mathrm{Cu}_{2} \mathrm{O}, \mathrm{Pd} / \mathrm{PdO}$, and $\mathrm{Ti} / \mathrm{TiO}_{2}$ core/shell spherical NPs with metal core radius $R=30 \mathrm{~nm}$ and dielectric shell thickness $d$ increasing from 0 to $80 \mathrm{~nm}$. In general the effect of increasing $d$ relies on an increasing of the intensity of the scattered light at $0^{\circ}$ with respect to the intensity of the light scattered at $180^{\circ}$. Regarding the $\mathrm{Ag} / \mathrm{Ag}_{2} \mathrm{O}$ NSPs: for $R=30 \mathrm{~nm}$ and $d=0 \mathrm{~nm}$, the intensity of the light scattered at $180^{\circ}$ is slightly higher than that scattered at $0^{\circ}$; this is the opposite with respect to the case for $R=30 \mathrm{~nm}$ and $d=20 \mathrm{~nm}$; very interesting is the situation obtained for $R=30 \mathrm{~nm}$ and $d=40 \mathrm{~nm}$, where the intensity of the light scattered at $0^{\circ}$ is about 3 times higher than the intensity of the light scattered at $180^{\circ}$; such a phenomenon is enhanced for $R=30 \mathrm{~nm}$ and $d=60 \mathrm{~nm}$ and for $R=30 \mathrm{~nm}$ and $d=$ $80 \mathrm{~nm}$. Concerning the $\mathrm{Al} / \mathrm{Al}_{2} \mathrm{O}_{3}$ NSPs: for $R=30 \mathrm{~nm}$ and $d=0 \mathrm{~nm}$, the intensity of the light scattered at $180^{\circ}$ is higher than that scattered at $0^{\circ}$ (more than the case of the $\mathrm{Ag} / \mathrm{Ag}_{2} \mathrm{O}$ NSPs); about the same are these intensities when $R=30 \mathrm{~nm}$ and $d=20 \mathrm{~nm}$; then increasing $d$ to 40,60 , and $80 \mathrm{~nm}$, the intensity of the light scattered at $0^{\circ}$ becomes higher than that scattered at $180^{\circ}$ (particularly evident for $d=80 \mathrm{~nm}$ ). About the $\mathrm{Cu} / \mathrm{Cu}_{2} \mathrm{O}$ NSPs: very similar are the intensities of the light scattered at $0^{\circ}$ and $180^{\circ}$; the intensity of the light

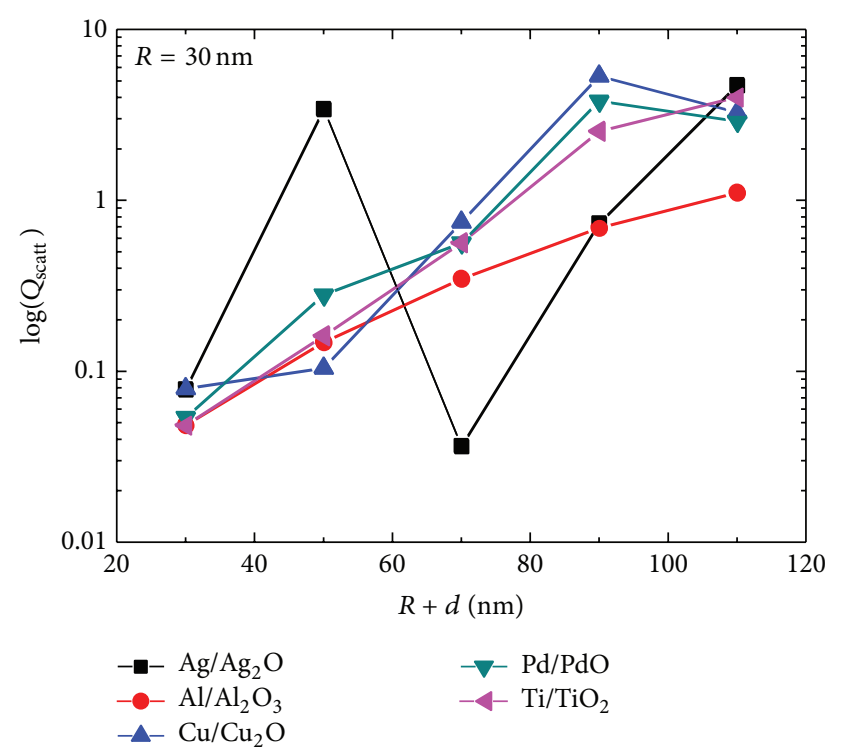

FIGURE 4: Scattering efficiency $Q_{\text {scatt }}$ (in semi-log scale) for $\mathrm{Ag} / \mathrm{Ag}_{2} \mathrm{O}, \mathrm{Al} / \mathrm{Al}_{2} \mathrm{O}_{3}, \mathrm{Cu} / \mathrm{Cu}_{2} \mathrm{O}, \mathrm{Pd} / \mathrm{PdO}$, and $\mathrm{Ti} / \mathrm{TiO}_{2}$ core/shell spherical NPs with metal core radius $R=30 \mathrm{~nm}$ and dielectric shell thickness $d$ increasing from 0 to $80 \mathrm{~nm}$.

scattered at $180^{\circ}$ becomes higher than that scattered at $0^{\circ}$ for $d=20,40,60$, and $80 \mathrm{~nm}$; this situation is more pronounced for $d=40 \mathrm{~nm}$ and less pronounced for $d=80 \mathrm{~nm}$. Regarding the Pd/PdO NSPs: while, for $R=30 \mathrm{~nm}$ and $d=0 \mathrm{~nm}$, the intensity of the light scattered at $0^{\circ}$ is lower than the intensity of the light scattered at $180^{\circ}$, the opposite situation is obtained for $d=20,40,60$, and $80 \mathrm{~nm}$, with particular enhancing for $d=60 \mathrm{~nm}$. Finally, concerning the $\mathrm{Ti} / \mathrm{TiO}_{2} \mathrm{NSPs}$ : the behavior is similar to the behavior of the $\mathrm{Pd} / \mathrm{PdO}$ NSPs, apart the case for $d=0 \mathrm{~nm}$. In this case, for the $\mathrm{Ti} / \mathrm{TiO}_{2} \mathrm{NSPs}$ the intensities of the light scattered at $0^{\circ}$ and $180^{\circ}$ are about the same.

In Figure 4 we report the calculated scattering efficiency $Q_{\text {scatt }}$ (in semi-log scale) for $\mathrm{Ag} / \mathrm{Ag}_{2} \mathrm{O}, \mathrm{Al} / \mathrm{Al}_{2} \mathrm{O}_{3}, \mathrm{Cu} / \mathrm{Cu}_{2} \mathrm{O}$, $\mathrm{Pd} / \mathrm{PdO}$, and $\mathrm{Ti} / \mathrm{TiO}_{2}$ core/shell spherical NPs with metal core radius $R=30 \mathrm{~nm}$ and dielectric shell thickness $d$ increasing from 0 to $80 \mathrm{~nm}$. Apart from the case of the $\mathrm{Ag} / \mathrm{Ag}_{2} \mathrm{O}$ NSPs, for the other types of core/shell NSPs an almost monotonic increase of $Q_{\text {scatt }}$ as a function of $d$ is obtained. For the $\mathrm{Ag} / \mathrm{Ag}_{2} \mathrm{O}$ NSPs, instead, a minimum value of $Q_{\text {scatt }}$ is obtained for $d=40 \mathrm{~nm}$ and a maximum value for $d=80 \mathrm{~nm}$.

In Figure 5 we report the calculated $I(\theta)$ polar diagrams for $\mathrm{Ag} / \mathrm{Ag}_{2} \mathrm{O}, \mathrm{Al} / \mathrm{Al}_{2} \mathrm{O}_{3}, \mathrm{Cu} / \mathrm{Cu}_{2} \mathrm{O}, \mathrm{Pd} / \mathrm{PdO}$, and $\mathrm{Ti} / \mathrm{TiO}_{2}$ core/shell spherical NPs with metal core radius $R=50 \mathrm{~nm}$ and dielectric shell thickness $d$ increasing from 0 to $60 \mathrm{~nm}$. Regarding the $\mathrm{Ag} / \mathrm{Ag}_{2} \mathrm{O}$ NSPs: for $R=50 \mathrm{~nm}$ and $d=0 \mathrm{~nm}$, the intensity of the light scattered at $180^{\circ}$ is slightly higher than that scattered at $0^{\circ}$, while it is about the same when $R=50 \mathrm{~nm}$ and $d=20 \mathrm{~nm}$; for $R=50 \mathrm{~nm}$ and $d=40 \mathrm{~nm}$, the intensity of the scattered light at $180^{\circ}$ is much higher than that scattered at $0^{\circ}$, while the opposite situation is obtained for $R=50 \mathrm{~nm}$ and $d=60 \mathrm{~nm}$. Concerning the $\mathrm{Al} / \mathrm{Al}_{2} \mathrm{O}_{3}$ 


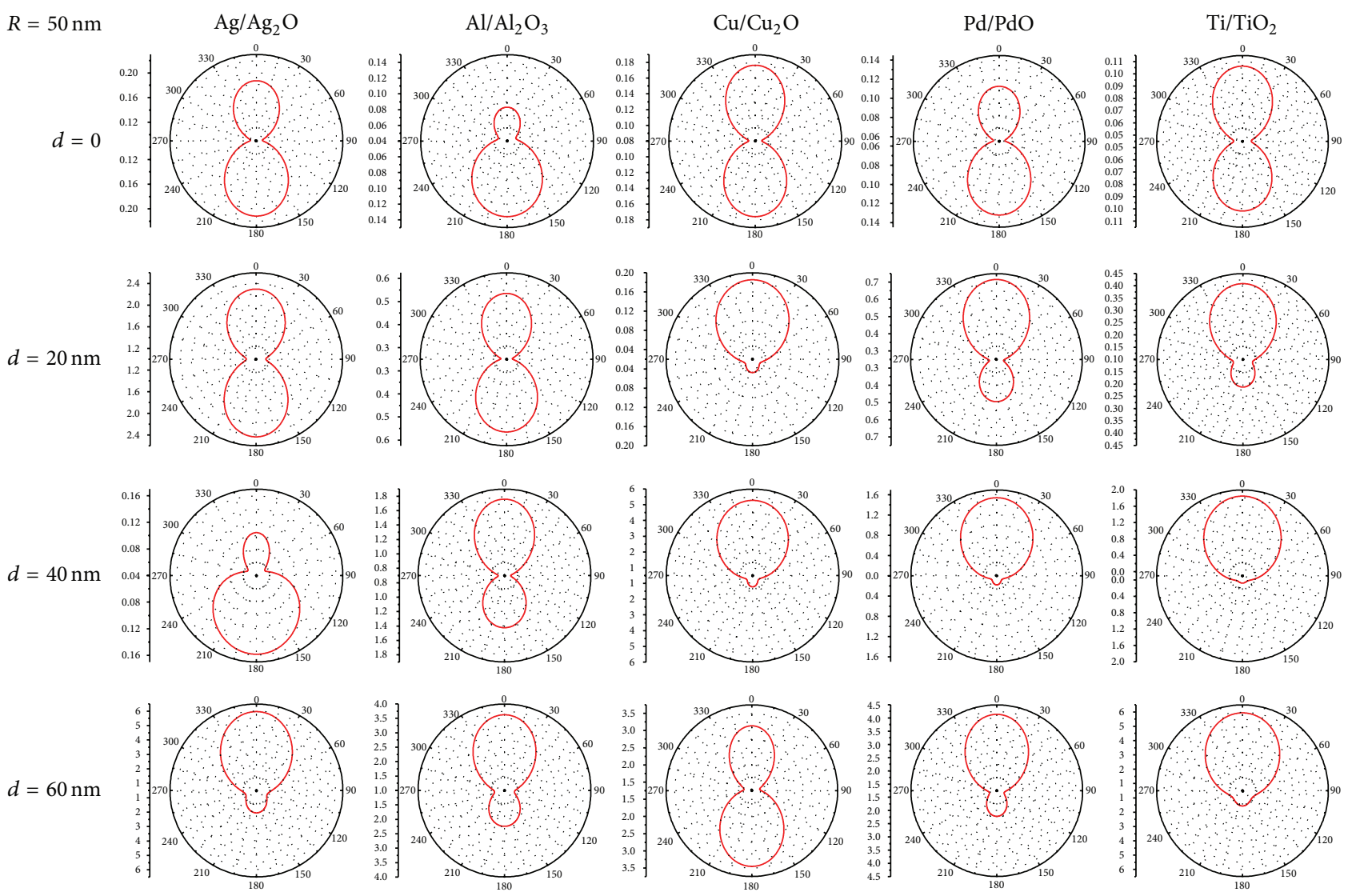

Figure 5: Calculated $I(\theta)$ polar diagrams for $\mathrm{Ag} / \mathrm{Ag}_{2} \mathrm{O}, \mathrm{Al} / \mathrm{Al}_{2} \mathrm{O}_{3}, \mathrm{Cu} / \mathrm{Cu}_{2} \mathrm{O}, \mathrm{Pd} / \mathrm{PdO}$, and $\mathrm{Ti} / \mathrm{TiO}_{2}$ core/shell spherical NPs with metal core radius $R=50 \mathrm{~nm}$ and dielectric shell thickness $d$ increasing from 0 to $60 \mathrm{~nm}$.

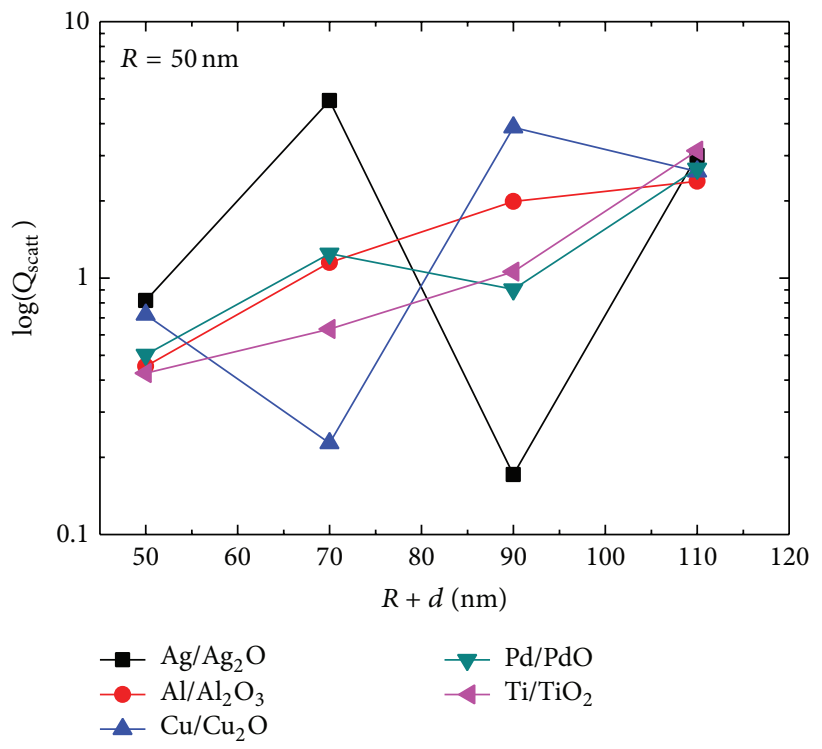

Figure 6: Scattering efficiency $\mathrm{Q}_{\text {scatt }}$ (in semi-log scale) for $\mathrm{Ag} / \mathrm{Ag}_{2} \mathrm{O}, \mathrm{Al} / \mathrm{Al}_{2} \mathrm{O}_{3}, \mathrm{Cu} / \mathrm{Cu}_{2} \mathrm{O}, \mathrm{Pd} / \mathrm{PdO}$, and Ti/TiO 2 core/shell spherical NPs with metal core radius $R=50 \mathrm{~nm}$ and dielectric shell thickness $d$ increasing from 0 to $60 \mathrm{~nm}$. 

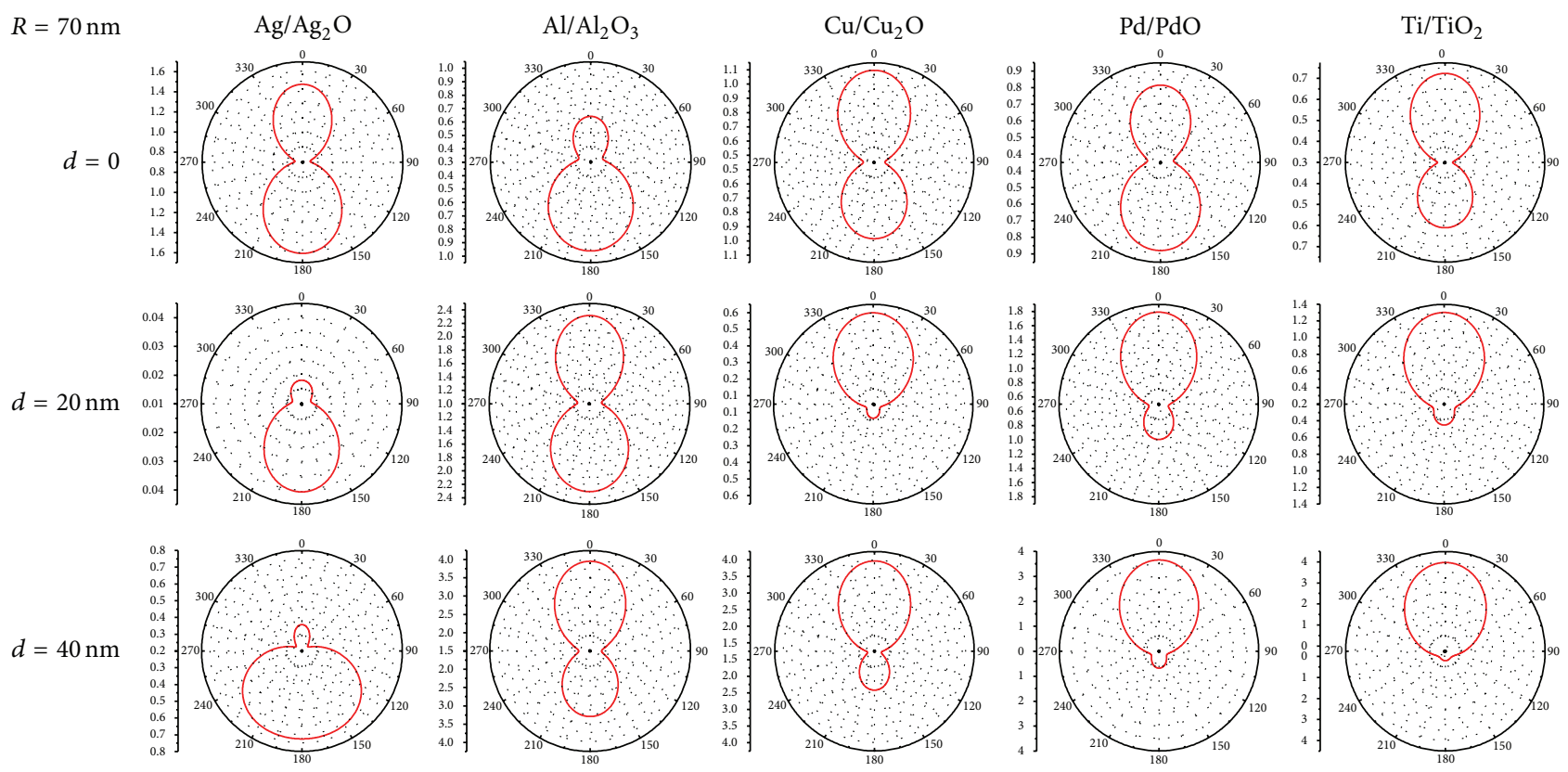

Figure 7: Calculated $I(\theta)$ polar diagrams for $\mathrm{Ag} / \mathrm{Ag}_{2} \mathrm{O}, \mathrm{Al} / \mathrm{Al}_{2} \mathrm{O}_{3}, \mathrm{Cu} / \mathrm{Cu}_{2} \mathrm{O}, \mathrm{Pd} / \mathrm{PdO}$, and $\mathrm{Ti} / \mathrm{TiO}_{2}$ core/shell spherical NPs with metal core radius $R=70 \mathrm{~nm}$ and dielectric shell thickness $d$ increasing from 0 to $40 \mathrm{~nm}$.

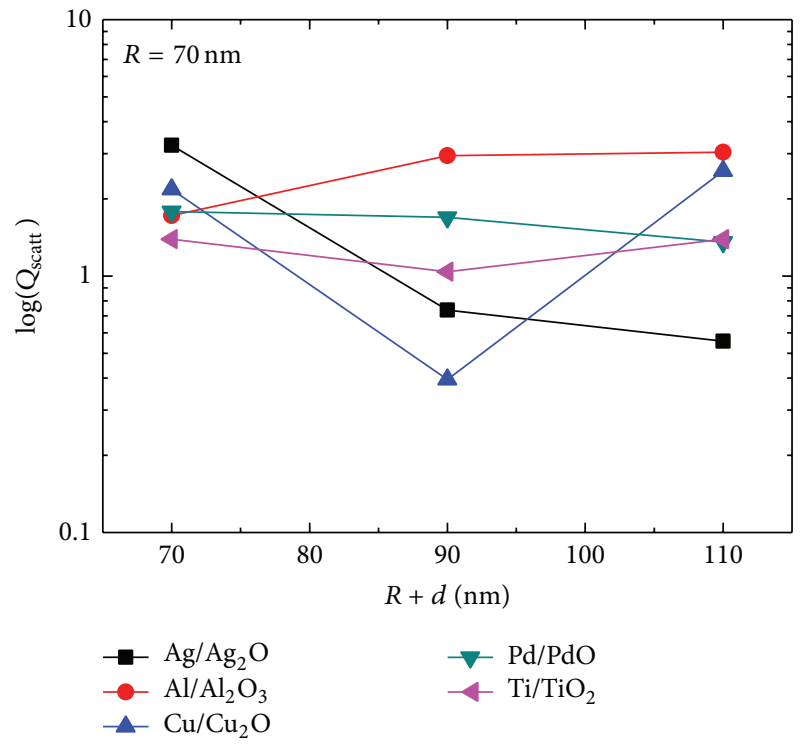

FIgURE 8: Scattering efficiency $Q_{\text {scatt }}$ (in semi-log scale) for $\mathrm{Ag} / \mathrm{Ag}_{2} \mathrm{O}, \mathrm{Al} / \mathrm{Al}_{2} \mathrm{O}_{3}, \mathrm{Cu} / \mathrm{Cu}_{2} \mathrm{O}, \mathrm{Pd} / \mathrm{PdO}$, and $\mathrm{Ti} / \mathrm{TiO}_{2}$ core/shell spherical NPs with metal core radius $R=70 \mathrm{~nm}$ and dielectric shell thickness $d$ increasing from 0 to $40 \mathrm{~nm}$.

NSPs: for $R=50 \mathrm{~nm}$ and $d=0 \mathrm{~nm}$, the intensity of the light scattered at $180^{\circ}$ is much higher than that scattered at $0^{\circ}$, while they are about the same when $R=50 \mathrm{~nm}$ and $d=20 \mathrm{~nm}$; for $R=50 \mathrm{~nm}$ and $d=40$ and $60 \mathrm{~nm}$, the intensity of the scattered light at $0^{\circ}$ is higher than that scattered at $180^{\circ}$. About the $\mathrm{Cu} / \mathrm{Cu}_{2} \mathrm{O}$ NSPs: for $R=50 \mathrm{~nm}$ and $d=0 \mathrm{~nm}$, the intensities of the scattered light at $0^{\circ}$ and $180^{\circ}$ are comparable, while for $R=50 \mathrm{~nm}$ and $d=20$ and $40 \mathrm{~nm}$ the intensity of the scattered light at $0^{\circ}$ is much higher than that scattered at $180^{\circ}$; for $R=50 \mathrm{~nm}$ and $d=60 \mathrm{~nm}$, the intensity of the light scattered at $180^{\circ}$ is slightly higher than that scattered at $0^{\circ}$. Regarding the Pd/PdO NSPs: for $R=50 \mathrm{~nm}$ and $d=0 \mathrm{~nm}$, the intensity of the light scattered at $180^{\circ}$ is higher than that scattered at $0^{\circ}$, while the opposite is the situation for $R=$ $50 \mathrm{~nm}$ and $d=20 \mathrm{~nm}$; for $R=50 \mathrm{~nm}$ and $d=40$ and $60 \mathrm{~nm}$, the intensity of the scattered light at $0^{\circ}$ is much higher than that scattered at $180^{\circ}$. Finally, concerning the $\mathrm{Ti} / \mathrm{TiO}_{2} \mathrm{NSPs}$ : while, for $R=50 \mathrm{~nm}$ and $d=0 \mathrm{~nm}$ the intensities of the scattered light at $0^{\circ}$ and $180^{\circ}$ are comparable, for $R=50 \mathrm{~nm}$ and $d=20,40$, and $60 \mathrm{~nm}$ the intensity of the scattered light at $0^{\circ}$ is much higher than that scattered at $180^{\circ}$.

In Figure 6 we report the calculated scattering efficiency $Q_{\text {scatt }}$ (in semi-log scale) for $\mathrm{Ag} / \mathrm{Ag}_{2} \mathrm{O}, \mathrm{Al} / \mathrm{Al}_{2} \mathrm{O}_{3}, \mathrm{Cu} / \mathrm{Cu}_{2} \mathrm{O}$, $\mathrm{Pd} / \mathrm{PdO}$, and $\mathrm{Ti} / \mathrm{TiO}_{2}$ core/shell spherical NPs with metal core radius $R=50 \mathrm{~nm}$ and dielectric shell thickness $d$ increasing from 0 to $60 \mathrm{~nm}$. While for the case of the $\mathrm{Al} / \mathrm{Al}_{2} \mathrm{O}_{3}$ and $\mathrm{Ti} / \mathrm{TiO}_{2}$ NSPs, $Q_{\text {scatt }}$ increases monotonically with $d$, for the $\mathrm{Ag} / \mathrm{Ag}_{2} \mathrm{O}$ and $\mathrm{Pd} / \mathrm{PdO}$ NSPs it presents a maximum value for $d=20 \mathrm{~nm}$ and a minimum one for $d=40 \mathrm{~nm}$; for the $\mathrm{Cu} / \mathrm{Cu}_{2} \mathrm{O}$ NSPs it presents a minimum value for $d=20 \mathrm{~nm}$ and a maximum one for $d=40 \mathrm{~nm}$.

In Figure 7 we report the calculated $I(\theta)$ polar diagrams for $\mathrm{Ag} / \mathrm{Ag}_{2} \mathrm{O}, \mathrm{Al} / \mathrm{Al}_{2} \mathrm{O}_{3}, \mathrm{Cu} / \mathrm{Cu}_{2} \mathrm{O}, \mathrm{Pd} / \mathrm{PdO}$, and $\mathrm{Ti} / \mathrm{TiO}_{2}$ core/shell spherical NPs with metal core radius $R=70 \mathrm{~nm}$ and dielectric shell thickness $d$ increasing from 0 to $40 \mathrm{~nm}$. Regarding the $\mathrm{Ag} / \mathrm{Ag}_{2} \mathrm{O}$ NSPs: for $R=70 \mathrm{~nm}$ and $d=0 \mathrm{~nm}$, the intensity of the light scattered at $180^{\circ}$ is slightly higher than that scattered at $0^{\circ}$; for $R=70 \mathrm{~nm}$ and $d=20$ and $40 \mathrm{~nm}$ it is much higher. Concerning the $\mathrm{Al} / \mathrm{Al}_{2} \mathrm{O}_{3}$ NSPs: for $R=70 \mathrm{~nm}$ and $d=0 \mathrm{~nm}$, the intensity of the light 

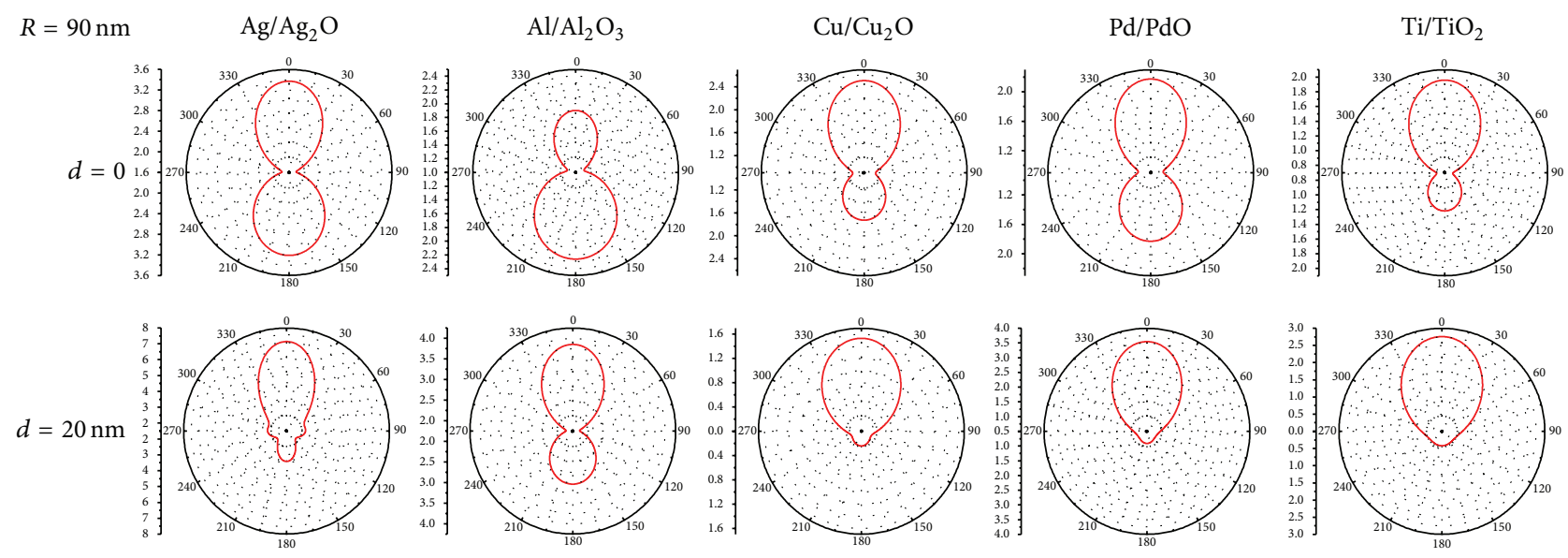

Figure 9: Calculated $I(\theta)$ polar diagrams for $\mathrm{Ag} / \mathrm{Ag}_{2} \mathrm{O}, \mathrm{Al} / \mathrm{Al}_{2} \mathrm{O}_{3}, \mathrm{Cu} / \mathrm{Cu}_{2} \mathrm{O}, \mathrm{Pd} / \mathrm{PdO}$, and $\mathrm{Ti} / \mathrm{TiO}_{2}$ core/shell spherical NPs with metal core radius $R=90 \mathrm{~nm}$ and dielectric shell thickness $d$ increasing from 0 to $20 \mathrm{~nm}$.

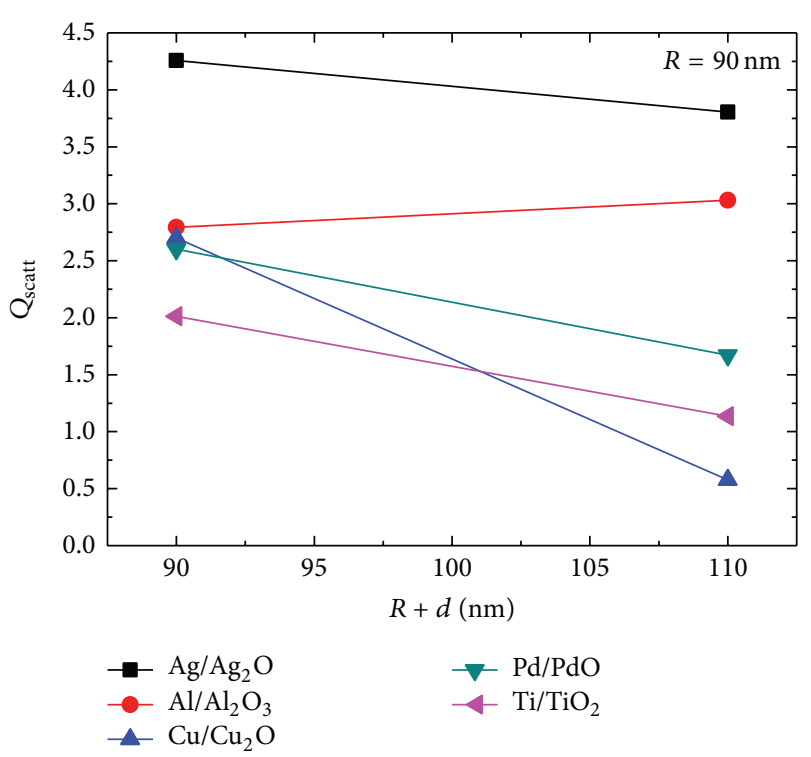

FIGURE 10: Scattering efficiency $Q_{\text {scatt }}$ (in semi-log scale) for $\mathrm{Ag} / \mathrm{Ag}_{2} \mathrm{O}, \mathrm{Al} / \mathrm{Al}_{2} \mathrm{O}_{3}, \mathrm{Cu} / \mathrm{Cu}_{2} \mathrm{O}, \mathrm{Pd} / \mathrm{PdO}$, and $\mathrm{Ti} / \mathrm{TiO}_{2}$ core/shell spherical NPs with metal core radius $R=90 \mathrm{~nm}$ and dielectric shell thickness $d$ increasing from 0 to $20 \mathrm{~nm}$.

scattered at $180^{\circ}$ is higher than that scattered at $0^{\circ}$, while they are comparable for $R=70 \mathrm{~nm}$ and $d=20 \mathrm{~nm}$; for $R=70 \mathrm{~nm}$ and $d=40 \mathrm{~nm}$, the intensity of the light scattered at $180^{\circ}$ is lower than that scattered at $0^{\circ}$. About the $\mathrm{Cu} / \mathrm{Cu}_{2} \mathrm{O}$ NSPs: for $R=70 \mathrm{~nm}$ and $d=0 \mathrm{~nm}$, the intensity of the light scattered at $180^{\circ}$ is slightly lower than that scattered at $0^{\circ}$, while for $R=70 \mathrm{~nm}$ and $d=20,40 \mathrm{~nm}$ it is much lower than that scattered at $0^{\circ}$. Regarding the Pd/PdO NSPs: for $R=70 \mathrm{~nm}$ and $d=0 \mathrm{~nm}$, the intensity of the light scattered at $180^{\circ}$ is slightly higher than that scattered at $0^{\circ}$, while for $R=70 \mathrm{~nm}$ and $d=20$ and $40 \mathrm{~nm}$ it is much lower than that scattered at $0^{\circ}$. Finally, concerning the $\mathrm{Ti} / \mathrm{TiO}_{2}$ NSPs: or $R=70 \mathrm{~nm}$ and $d=0 \mathrm{~nm}$, the intensity of the light scattered at $180^{\circ}$ is slightly lower than that scattered at $0^{\circ}$, while for $R=70 \mathrm{~nm}$ and $d=20$ and $40 \mathrm{~nm}$ it is much lower than that scattered at $0^{\circ}$.

In Figure 8 we report the calculated scattering efficiency $Q_{\text {scatt }}$ (in semi-log scale) for $\mathrm{Ag} / \mathrm{Ag}_{2} \mathrm{O}, \mathrm{Al} / \mathrm{Al}_{2} \mathrm{O}_{3}, \mathrm{Cu} / \mathrm{Cu}_{2} \mathrm{O}$, $\mathrm{Pd} / \mathrm{PdO}$, and $\mathrm{Ti} / \mathrm{TiO}_{2}$ core/shell spherical NPs with metal core radius $R=70 \mathrm{~nm}$ and dielectric shell thickness $d$ increasing from 0 to $40 \mathrm{~nm}$. Regarding the $\mathrm{Ag} / \mathrm{Ag}_{2} \mathrm{O}$ NSPs, $Q_{\text {scatt }}$ decreases monotonically when $d$ increases. Concerning the $\mathrm{Al} / \mathrm{Al}_{2} \mathrm{O}_{3}$ NSPs it increases monotonically when $d$ increases. About the $\mathrm{Cu} / \mathrm{Cu}_{2} \mathrm{O}$ NSPs, $Q_{\text {scatt }}$ decreases when $d$ passes from 0 to $20 \mathrm{~nm}$ and increases when $d$ passes from 20 to $40 \mathrm{~nm}$. Regarding the $\mathrm{Pd} / \mathrm{PdO}$ and $\mathrm{Ti} / \mathrm{TiO}_{2}$ NSPs it is constant with $d$.

In Figure 9 we report the calculated $I(\theta)$ polar diagrams for $\mathrm{Ag} / \mathrm{Ag}_{2} \mathrm{O}, \mathrm{Al} / \mathrm{Al}_{2} \mathrm{O}_{3}, \mathrm{Cu} / \mathrm{Cu}_{2} \mathrm{O}, \mathrm{Pd} / \mathrm{PdO}$, and $\mathrm{Ti} / \mathrm{TiO}_{2}$ core/shell spherical NPs with metal core radius $R=90 \mathrm{~nm}$ and dielectric shell thickness $d$ increasing from 0 to $20 \mathrm{~nm}$. Regarding the $\mathrm{Ag} / \mathrm{Ag}_{2} \mathrm{O}$ NSPs: for $R=90 \mathrm{~nm}$ and $d=$ $0 \mathrm{~nm}$, the intensities of the light scattered at $0^{\circ}$ and $180^{\circ}$ are comparable, while for $R=90 \mathrm{~nm}$ and $d=20 \mathrm{~nm}$, the intensity of the light scattered at $0^{\circ}$ is much higher than that scattered at $180^{\circ}$. Concerning the $\mathrm{Al} / \mathrm{Al}_{2} \mathrm{O}_{3}$ NSPs: for $R=$ $90 \mathrm{~nm}$ and $d=0 \mathrm{~nm}$, the intensity of the light scattered at $180^{\circ}$ is higher than that scattered at $0^{\circ}$, while the opposite is the case for $R=90 \mathrm{~nm}$ and $d=20 \mathrm{~nm}$. About the $\mathrm{Cu} / \mathrm{Cu}_{2} \mathrm{O}$ NSPs: for $R=90 \mathrm{~nm}$ and $d=0 \mathrm{~nm}$, the intensity of the light scattered at $180^{\circ}$ is higher than that scattered at $0^{\circ}$, and this difference is enhanced for $R=90 \mathrm{~nm}$ and $d=20 \mathrm{~nm}$. A similar behavior for the $\mathrm{Pd} / \mathrm{PdO}$ and $\mathrm{Ti} / \mathrm{TiO}_{2}$ NSPs.

In Figure 10, we report the calculated scattering efficiency $Q_{\text {scatt }}$ (in semi-log scale) for $\mathrm{Ag} / \mathrm{Ag}_{2} \mathrm{O}, \mathrm{Al} / \mathrm{Al}_{2} \mathrm{O}_{3}, \mathrm{Cu} / \mathrm{Cu}_{2} \mathrm{O}$, $\mathrm{Pd} / \mathrm{PdO}$, and $\mathrm{Ti} / \mathrm{TiO}_{2}$ core/shell spherical NPs with metal core radius $R=90 \mathrm{~nm}$ and dielectric shell thickness $d$ increasing from 0 to $20 \mathrm{~nm}$. $Q_{\text {scatt }}$ is the highest and 

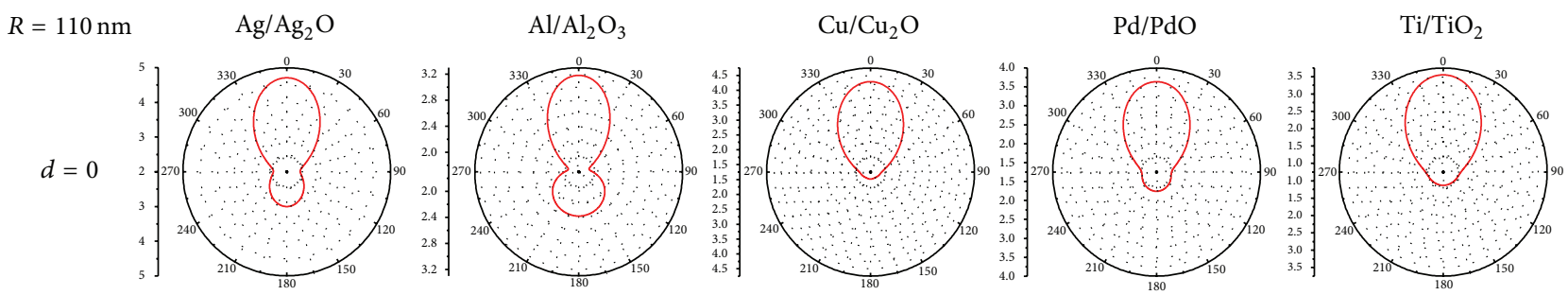

Figure 11: Calculated $I(\theta)$ polar diagrams for $\mathrm{Ag} / \mathrm{Ag}_{2} \mathrm{O}, \mathrm{Al} / \mathrm{Al}_{2} \mathrm{O}_{3}, \mathrm{Cu} / \mathrm{Cu}_{2} \mathrm{O}, \mathrm{Pd} / \mathrm{PdO}$, and $\mathrm{Ti} / \mathrm{TiO}_{2}$ core/shell spherical NPs with metal core radius $R=110 \mathrm{~nm}$ and dielectric shell thickness $d=0 \mathrm{~nm}$.

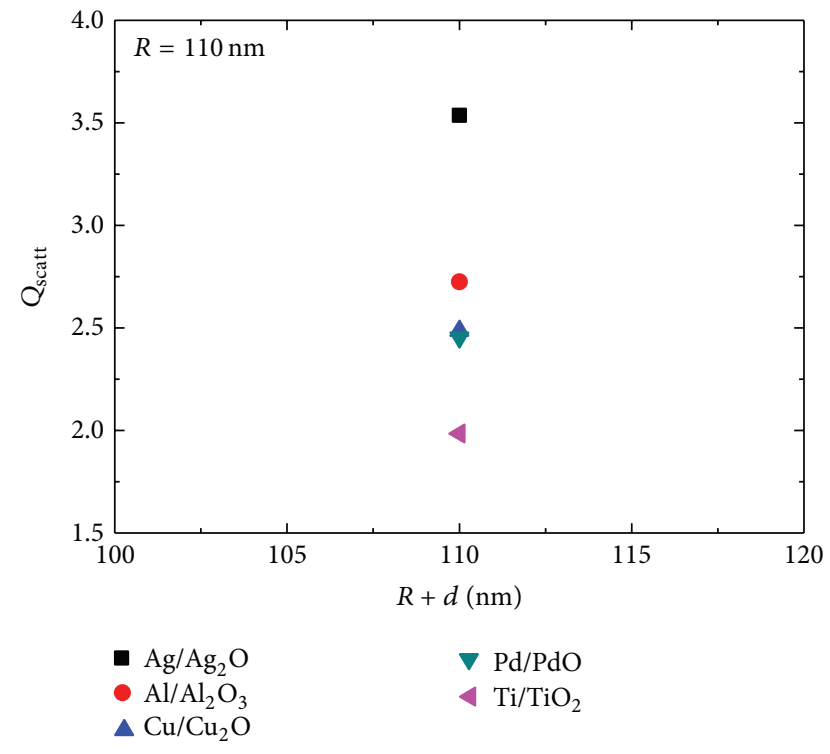

FIGURE 12: Scattering efficiency $Q_{\text {scatt }}$ (in semi-log scale) for $\mathrm{Ag} / \mathrm{Ag}_{2} \mathrm{O}, \mathrm{Al} / \mathrm{Al}_{2} \mathrm{O}_{3}, \mathrm{Cu} / \mathrm{Cu}_{2} \mathrm{O}, \mathrm{Pd} / \mathrm{PdO}$, and $\mathrm{Ti} / \mathrm{TiO}_{2}$ core/shell spherical NPs with metal core radius $R=110 \mathrm{~nm}$ and dielectric shell thickness $d=0 \mathrm{~nm}$.

is constant with $d$, for the $\mathrm{Ag} / \mathrm{Ag}_{2} \mathrm{O}$ NSPs. Lower values are obtained for the $\mathrm{Al} / \mathrm{Al}_{2} \mathrm{O}_{3}$ NSPs. Furtehr lower values are obtained for the $\mathrm{Pd} / \mathrm{PdO}$ and $\mathrm{Ti} / \mathrm{TiO}_{2}$ NSPs. For the $\mathrm{Cu} / \mathrm{Cu}_{2} \mathrm{O}$ NSPs, the value of $Q_{\text {scatt }}$ is comparable to the one obtained for the $\mathrm{Al} / \mathrm{Al}_{2} \mathrm{O}_{3}$ and $\mathrm{Pd} / \mathrm{PdO}$ NSPs for $d=0 \mathrm{~nm}$, while its value is the minimum one for $d=20 \mathrm{~nm}$.

In Figure 11 we report the calculated $I(\theta)$ polar diagrams for $\mathrm{Ag} / \mathrm{Ag}_{2} \mathrm{O}, \mathrm{Al} / \mathrm{Al}_{2} \mathrm{O}_{3}, \mathrm{Cu} / \mathrm{Cu}_{2} \mathrm{O}, \mathrm{Pd} / \mathrm{PdO}$, and $\mathrm{Ti} / \mathrm{TiO}_{2}$ core/shell spherical NPs with metal core radius $R=110 \mathrm{~nm}$ and dielectric shell thickness $d=0 \mathrm{~nm}$. In any case, the intensity of the scattered light at $0^{\circ}$ is higher than that scattered at $180^{\circ}$.

In Figure 12 we report the calculated scattering efficiency $Q_{\text {scatt }}$ (in semi-log scale) for $\mathrm{Ag} / \mathrm{Ag}_{2} \mathrm{O}, \mathrm{Al} / \mathrm{Al}_{2} \mathrm{O}_{3}, \mathrm{Cu} / \mathrm{Cu}_{2} \mathrm{O}$, $\mathrm{Pd} / \mathrm{PdO}$, and $\mathrm{Ti} / \mathrm{TiO}_{2}$ core/shell spherical NPs with metal core radius $R=110 \mathrm{~nm}$ and dielectric shell thickness $d=$ $0 \mathrm{~nm}$. It is the highest for the $\mathrm{Ag} / \mathrm{Ag}_{2} \mathrm{O}$ NSPs. Then it is lower, in order, for the $\mathrm{Al} / \mathrm{Al}_{2} \mathrm{O}_{3}, \mathrm{Cu} / \mathrm{Cu}_{2} \mathrm{O}, \mathrm{Pd} / \mathrm{PdO}$, and $\mathrm{Ti} / \mathrm{TiO}_{2}$ NSPs.

\section{Conclusion}

In conclusion, in this work we reported theoretical results of angle-dependent light scattering intensity and scattering efficiency for $\mathrm{Ag} / \mathrm{Ag}_{2} \mathrm{O}, \mathrm{Al} / \mathrm{Al}_{2} \mathrm{O}_{3}, \mathrm{Cu} / \mathrm{Cu}_{2} \mathrm{O}, \mathrm{Pd} / \mathrm{PdO}$, and $\mathrm{Ti} / \mathrm{TiO}_{2}$ core/shell NPs increasing the radius of the metal core from 30 to $110 \mathrm{~nm}$ and the thickness of the dielectric shell from 0 to $80 \mathrm{~nm}$. For various geometrical conditions the $I(\theta)$ diagram and scattering efficiency $Q_{\text {scatt }}$ were calculated and they can be compared for the different core/shell NPs for the different combination of sizes of the core and of the shell. Combining the $I(\theta)$ and $Q_{\text {scatt }}$ information, the best geometry for the metal/dielectric core/shell NPs can be chosen for a specific application involving a particular scattering properties of the system. Furthermore, our approach is broadly applicable rather than a relic of the parameters that we investigated in this work. A similar simulation can be performed, within the Mie theoretical framework, for homogeneous or layered particles of any materials embedded in any medium.

\section{Conflict of Interests}

The authors declare that there is no conflict of interests regarding thepublication of this paper.

\section{References}

[1] E. Ozbay, "Plasmonics: merging photonics and electronics at nanoscale dimensions," Science, vol. 311, no. 5758, pp. 189-193, 2006.

[2] S. A. Maier, Plasmonics: Fundamentals and Applications, Springer, New York, NY, USA, 2007.

[3] P. K. Jain, X. Huang, I. H. El-Sayed, and M. A. El-Sayed, "Review of some interesting surface plasmon resonance-enhanced properties of noble metal nanoparticles and their applications to biosystems," Plasmonics, vol. 2, no. 3, pp. 107-118, 2007.

[4] H. A. Atwater and A. Polman, "Plasmonics for improved photovoltaic devices," Nature Materials, vol. 9, no. 3, pp. 205213,2010

[5] Y. Lei and W.-K. Chim, "Highly ordered arrays of metal/ semiconductor core-shell nanoparticles with tunable nanostructures and photoluminescence," Journal of the American Chemical Society, vol. 127, no. 5, pp. 1487-1492, 2005.

[6] L. R. Hirsch, R. J. Stafford, J. A. Bankson et al., "Nanoshellmediated near-infrared thermal therapy of tumors under magnetic resonance guidance," Proceedings of the National Academy 
of Sciences of the United States of America, vol. 100, no. 23, pp. 13549-13554, 2003.

[7] J. Z. Zhang, "Biomedical applications of shape-controlled plasmonic nanostructures: a case study of hollow gold nanospheres for photothermal ablation therapy of cancer," Journal of Physical Chemistry Letters, vol. 1, no. 4, pp. 686-695, 2010.

[8] G. Baffou, R. Quidant, and C. Girard, "Heat generation in plasmonic nanostructures: influence of morphology," Applied Physics Letters, vol. 94, no. 15, Article ID 153109, 2009.

[9] S. D. Hudson and G. Chumanov, "Surface enhanced Raman scattering and resonance elastic scattering from capped single Ag nanoparticles," Journal of Physical Chemistry C, vol. 112, no. 50, pp. 19866-19871, 2008.

[10] L. Gao and X. P. Yu, "Second- and third-harmonic generations for a nondilute suspension of coated particles with radial dielectric anisotropy," European Physical Journal B, vol. 55, no. 4, pp. 403-409, 2007.

[11] P. Alivisatos, "The use of nanocrystals in biological detection," Nature Biotechnology, vol. 22, no. 1, pp. 47-52, 2004.

[12] J. Zhu, "Enhanced fluorescence from $\mathrm{Dy}^{3+}$ owing to surface plasmon resonance of Au colloid nanoparticles," Materials Letters, vol. 59, no. 11, pp. 1413-1416, 2005.

[13] N. Pinçon, B. Palpant, D. Prot, E. Charron, and S. Debrus, "Third-order nonlinear optical response of $\mathrm{Au}: \mathrm{SiO}_{2}$ thin films: influence of gold nanoparticle concentration and morphologic parameters," European Physical Journal D, vol. 19, no. 3, pp. 395$402,2002$.

[14] L. Gao, L. Gu, and Z. Li, "Optical bistability and tristability in nonlinear metal/dielectric composite media of nonspherical particles," Physical Review E: Statistical, Nonlinear, and Soft Matter Physics, vol. 68, no. 6, Article ID 066601, 2003.

[15] M. Quinten, Optical Properties of Nanoparticle Systems, WileyVCH, Berlin, Germany, 2011.

[16] A. A. Maradudin, Light Scattering and Nanoscale Surface Roughness, Springer, New York, NY, USA, 2011.

[17] C. F. Bohren and D. R. Huffman, Absorption and Scattering of Light by Small Particles, Wiley-VCH, Berlin, Germany, 2004.

[18] M. I. Mishchenko, 1. D. Travi, and A. A. Lacis, Scattering, Absorption, and Emission of Light by Small Particles, Cambridge University Press, Cambridge, UK, 2002.

[19] D. C. Schinca and L. B. Scaffardi, "Core and shell sizing of small silver-coated nanospheres by optical extinction spectroscopy," Nanotechnology, vol. 19, no. 49, Article ID 495712, 2008.

[20] D. Qu, F. Liu, J. Yu et al., "Plasmonic core-shell gold nanoparticle enhanced optical absorption in photovoltaic devices," Applied Physics Letters, vol. 98, no. 11, Article ID 113119, 2011.

[21] H. Baida, P. Billaud, S. Marhaba et al., "Quantitative determination of the size dependence of surface plasmon resonance damping in single Ag@SiO $\mathrm{S}_{2}$ nanoparticles," Nano Letters, vol. 9, no. 10, pp. 3463-3469, 2009.

[22] F. Ruffino, A. Pugliara, E. Carria et al., "Novel approach to the fabrication of $\mathrm{Au} /$ silica coreshell nanostructures based on nanosecond laser irradiation of thin Au films on Si," Nanotechnology, vol. 23, no. 4, Article ID 045601, 2012.

[23] G. Valverde-Aguillar, J. A. García-Macedo, and V. RenteríaTapia, "Silver core-silver oxide shell nanoparticles embedded on mesostructured silica films," Journal of Nano Research, vol. 3, pp. 103-114, 2008.

[24] J. Ghilane, F.-R. F. Fan, A. J. Bard, and N. Dunwoody, "Facile electrochemical characterization of core/shell nanoparticles. Ag core/ $\mathrm{Ag}_{2} \mathrm{O}$ shell structures," Nano Letters, vol. 7, no. 5, pp. 14061412, 2007.
[25] V. A. Karavanskii, A. V. Simakin, V. I. Krasovskii, and P. V. Ivanchenko, "Nonlinear optical properties of colloidal silver nanoparticles produced by laser ablation in liquids," Quantum Electronics, vol. 34, no. 7, pp. 644-648, 2004.

[26] J. M. J. Santillán, L. B. Scaffardi, and D. C. Schinca, "Quantitative optical extinction-based parametric method for sizing a single core-shell Ag- $\mathrm{Ag}_{2} \mathrm{O}$ nanoparticle," Journal of Physics D: Applied Physics, vol. 44, no. 10, Article ID 105104, 2011.

[27] A. Kuzma, M. Weis, S. Flickyngerova et al., "Influence of surface oxidation on plasmon resonance in monolayer of gold and silver nanoparticles," Applied Physics Letters, vol. 112, Article ID 103531, 2012.

[28] Z. Yang, L. He, J. Chen, H. Cong, and H. Ye, "Microstructure and thermal stability of an ultrafine $\mathrm{Al} / \mathrm{Al}_{2} \mathrm{O}_{3}$ composite," Journal of Materials Research, vol. 18, no. 2, pp. 272-278, 2003.

[29] H. Kou, J. Guo, J. Wang, and Y. Pan, " $\mathrm{Al} / \mathrm{Al}_{2} \mathrm{O}_{3}$ core-shell particles synthesized by wet-chemical based route," Key Engineering Materials, vol. 313, pp. 63-68, 2006.

[30] Y.-J. Peng, S.-P. Zhang, Y.-H. Wang, and Y.-Q. Yang, “Theoretical investigation on near-infrared and visible absorption spectra of nanometallic aluminium with oxide coating in nanoenergetic materials: size and shape effects," Chinese Physics B, vol. 17, no. 9, pp. 3505-3511, 2008.

[31] S. Das, S. Datta, A. K. Mukhopadhyay, K. S. Pal, and D. Basu, "Al- $\mathrm{Al}_{2} \mathrm{O}_{3}$ core-shell composite by microwave induced oxidation of aluminium powder," Materials Chemistry and Physics, vol. 122, no. 2-3, pp. 574-581, 2010.

[32] S. B. Kalidindi, U. Sanyal, and B. R. Jagirdar, "Nanostructured $\mathrm{Cu}$ and $\mathrm{Cu} @ \mathrm{Cu}_{2} \mathrm{O}$ core shell catalysts for hydrogen generation from ammonia-borane," Physical Chemistry Chemical Physics, vol. 10, no. 38, pp. 5870-5874, 2008.

[33] T. Ghodselahi, M. A. Vesaghi, A. Shafiekhani, A. Baghizadeh,

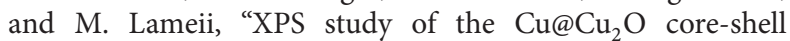
nanoparticles," Applied Surface Science, vol. 255, no. 5, pp. 27302734, 2008.

[34] T. Ghodselahi, M. A. Vesaghi, and A. Shafiekhani, "Study of surface plasmon resonance of $\mathrm{Cu} @ \mathrm{Cu}, \mathrm{sub}_{\dot{2}} 2 \mathrm{O}$ core-shell nanoparticles by Mie theory," Journal of Physics D: Applied Physics, vol. 42, no. 1, Article ID 015308, 2009.

[35] O. Peña-Rodríguez and P. Umapada, "Effects of surface oxidation on the linear optical properties of $\mathrm{Cu}$ nanoparticles," Journal of the Optical Society of America B, vol. 28, pp. 27352739, 2011.

[36] A. Radi, D. Pradhan, Y. Sohn, and K. T. Leung, "Nanoscale shape and size control of cubic, cuboctahedral, and octahedral Cu$\mathrm{Cu}_{2} \mathrm{O}$ core-shell nanoparticles on $\mathrm{Si}(100)$ by one-step, templateless, capping-agent-free electrodeposition," ACS Nano, vol. 4, no. 3, pp. 1553-1560, 2010.

[37] Y. Xiong, J. Chen, B. Wiley, Y. Xia, Y. Yin, and Z.-Y. Li, “Sizedependence of surface plasmon resonance and oxidation for Pd nanocubes synthesized via a seed etching process," Nano Letters, vol. 5, no. 7, pp. 1237-1242, 2005.

[38] D. Jose and B. R. Jagirdar, "Synthesis and characterization of Pd(0), PdS, and Pd@PdO core-shell nanoparticles by solventless thermolysis of a Pd-thiolate cluster," Journal of Solid State Chemistry, vol. 183, no. 9, pp. 2059-2067, 2010.

[39] D. Kumar and R. K. Soni, "Formation of Ti/TiO2Nanoparticles by Laser Ablation in Ethanol," in DAE-BRNS 5thNational Symposium on Pulsed Laser Deposition of Thin Films and Nanostructured Materials, 2009.

[40] G. Mie, "Beitrage zer Optik truber Meiden speziell kolloidaler Metallosungen," Annalen der Physik, vol. 25, pp. 377-445, 1908. 
[41] A. F. Huxley, "A theoretical treatment of the reflexion of light by multilayer structures," Journal of Experimental Biology, vol. 48, pp. 227-245, 1968.

[42] A. Small, S. Hong, and D. Pine, "Scattering properties of coreshell particles in plastic matrices," Journal of Polymer Science. Part B: Polymer Physics, vol. 43, no. 24, pp. 3534-3548, 2005.

[43] V. Bazhan, "SCATLAB Version 1. 2," http://www.scatlab.com/ index.html.

[44] http://refractiveindex.info/.

[45] E. D. Palik, Handbook of Optical Constants of Solids, Academic Press, New York, NY, USA, 1985.

[46] F. Pei, S. Wu, G. Wang et al., "Electronic and optical properties of noble metal oxides $\mathrm{M}_{2} \mathrm{O}(\mathrm{M}=\mathrm{Cu}, \mathrm{Ag}$ and $\mathrm{Au})$ : first-principles study," Journal of the Korean Physical Society, vol. 55, pp. 12431249, 2009. 

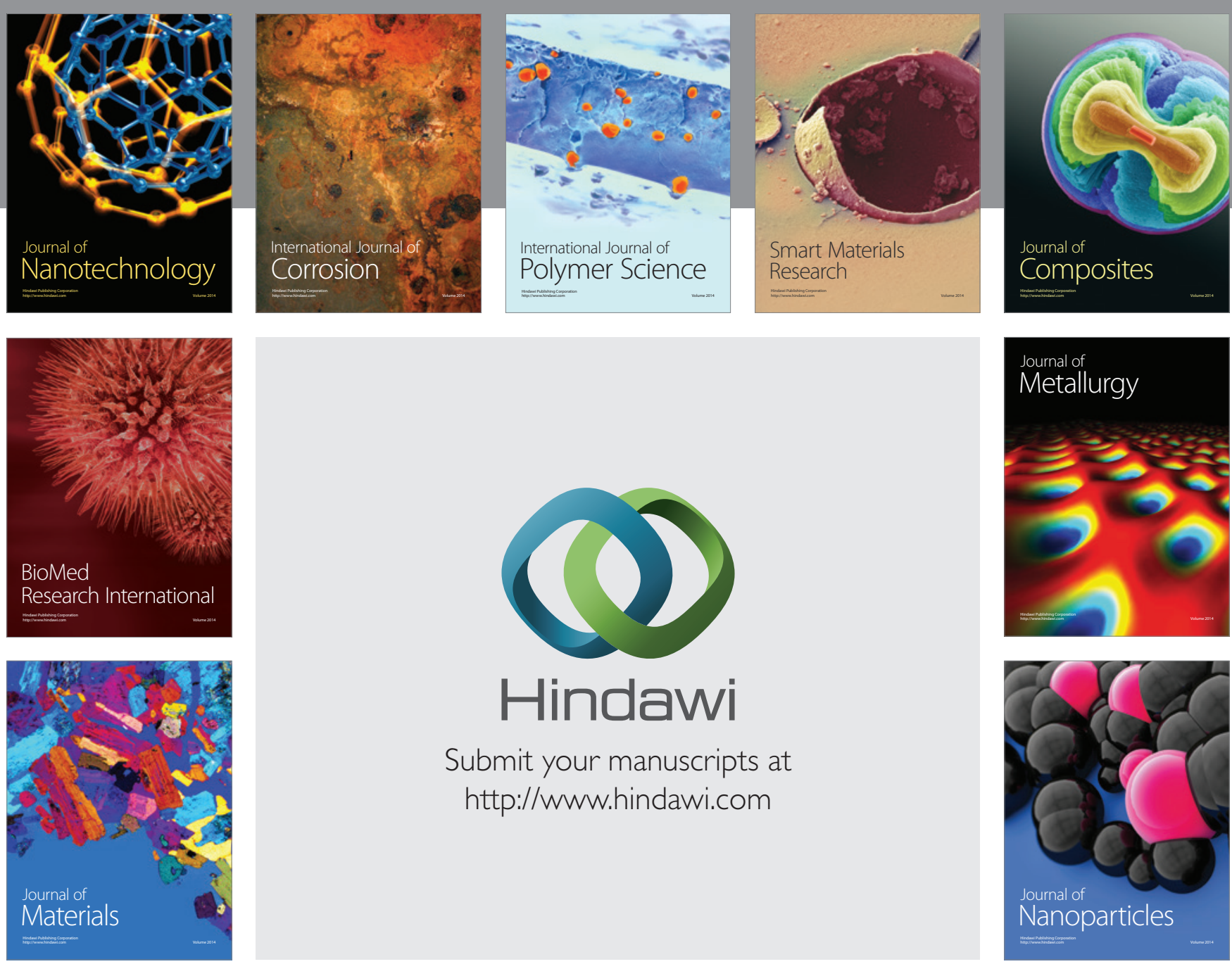

Submit your manuscripts at http://www.hindawi.com
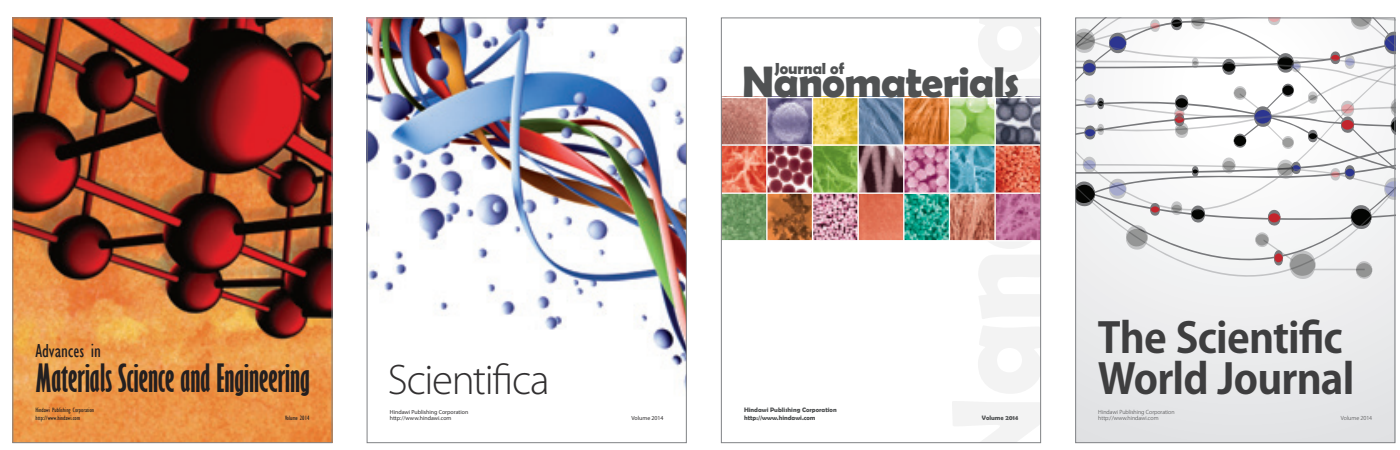

\section{The Scientific World Journal}
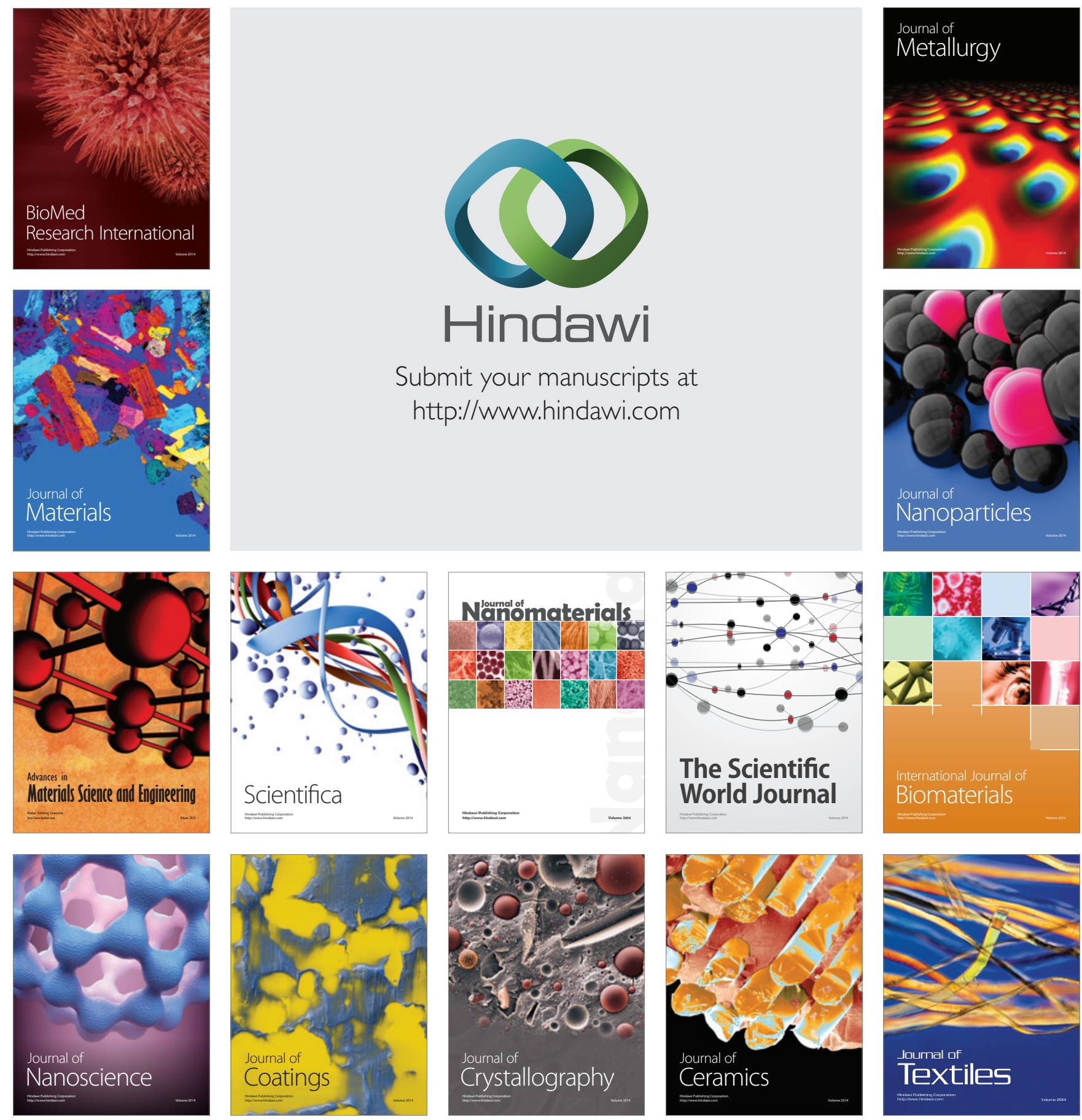